\title{
Guidelines
}

\section{Consensus-Based Care Recommendations for Pulmonologists Treating Adults with Myotonic Dystrophy Type 1}

\author{
Matthias Boentert ${ }^{\mathrm{a}} \quad$ Michelle Cao $^{\mathrm{b}}$ Daphne Maas $^{c} \quad$ Elisa De Mattia ${ }^{\mathrm{d}}$ \\ Elisa Falcier ${ }^{d}$ Miguel Goncalves ${ }^{e}$ Venessa Holland ${ }^{f}$ Sherri Lynne Katz ${ }^{g}$ \\ David Orlikowski $^{\text {h }}$ Giulia Sannicolò ${ }^{d}$ Peter Wijkstra ${ }^{i}$ Leah Hellerstein ${ }^{j}$ \\ Valeria A. Sansone ${ }^{d}$

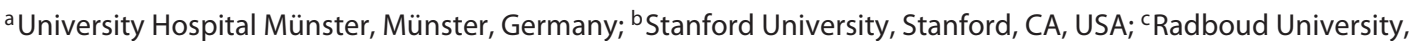 \\ Nijmegen, The Netherlands; ${ }^{d}$ The NEMO Clinical Center (NEuroMuscular Omniservice), University of Milan, \\ Milan, Italy; ${ }^{e}$ Centro Hospitalar de São João, São João, Portugal; ${ }^{f}$ Houston Methodist Neurological Institute,

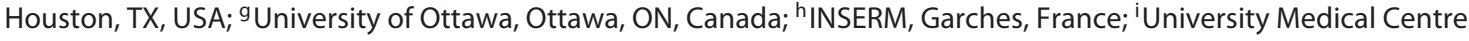

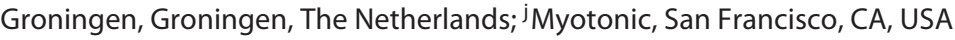

\section{Keywords}

Guidelines · Muscular dystrophy - Myotonic dystrophy .

Respiration · Respiratory care $\cdot$ Respiratory care

recommendations

\begin{abstract}
Purpose of Review: Myotonic dystrophy type 1 (DM1) is a severe, progressive genetic disease that affects approximately 1 in 2,500 individuals globally [Ashizawa et al.: Neurol Clin Pract 2018;8(6):507-20]. In patients with DM1, respiratory muscle weakness frequently evolves, leading to respiratory failure as the main cause of death in this patient population, followed by cardiac complications [de Die-Smulders et al.: Brain 1998;121(Pt 8):1557-63], [Mathieu et al.: Neurology 1999;52(8):1658-62], [Groh et al.: Muscle Nerve 2011;43(5): 648-51]. This paper provides a more detailed outline on the diagnostic and management protocols, which can guide pulmonologists who may not have experience with DM1 or who are not part of a neuromuscular multidisciplinary clinic. A group of neuromuscular experts in DM1 including pulmonologists, respiratory physiotherapists and sleep specialists discussed respiratory testing and management at baseline
\end{abstract}

karger@karger.com

(c) 2020 S. Karger AG, Basel

www.karger.com/res

Karger! and during follow-up visits, based on their clinical experience with patients with DM1. The details are presented in this report. Recent Findings: Myotonic recruited 66 international clinicians experienced in the treatment of people living with DM1 to develop and publish consensus-based care recommendations targeting all body systems affected by this disease [Ashizawa et al.: Neurol Clin Pract. 2018;8(6): 507-20]. Myotonic then worked with 12 international respiratory therapists, pulmonologists and neurologists with long-standing experience in DM respiratory care to develop consensus-based care recommendations for pulmonologists using a methodology called the Single Text Procedure. This process generated a 7-page document that provides detailed respiratory care recommendations for the management of patients living with DM1. This consensus is completely based on expert opinion and not backed up by empirical evidence due to limited clinical care data available for respiratory care management in DM patients. Nevertheless, we believe it is of relevance for professionals treating adults with myotonic dystrophy because it addresses practical issues related to respiratory management and care, which have been adapted to meet the specific issues in patients with DM1. Summary: The resulting recommendations are 
intended to improve respiratory care for the most vulnerable of DM1 patients and lower the risk of untoward respiratory complications and mortality by providing pulmonologist who are less experienced with DM1 with practical indications on which tests and when to perform them, adapting the general respiratory knowledge to specific issues related to this multiorgan disease.

(c) 2020 S. Karger AG, Base

\section{Introduction}

Myotonic dystrophy type 1 (DM1) is a hereditary autosomal dominant disorder, caused by multiple repetitions of an unstable trinucleotide (CTG) in the region of the dystrophia myotonica protein kinase gene at chromosome 19q13.3 [1]. Population-based (not diagnosed) prevalence is $1: 2,500$ [2]. DM1 is a multisystem disorder involving not only skeletal and smooth muscles, but also visual, cardiac, endocrine, central nervous system, digestive and respiratory systems [3]. Respiratory failure is the primary cause of death, and in adult-onset patients with DM1 typically occurs between 50 and 60 years of age [4-6].

There is general consensus that respiratory involvement in myotonic dystrophy is due to a combination of peripheral (respiratory and bulbar muscle weakness) and central (brain stem and CNS pathways) components [715]. Weakness of the inspiratory and expiratory muscles reduces cough efficacy, which impairs airway clearance, leading to an increased risk of aspiration and pulmonary infections [16-18]. In addition, weakness of the swallowing muscles increases the risk of aspiration of solids and liquid, saliva, nasal secretions and stomach fluids. Clinical experience and reports from patients and families indicate that acute respiratory failure may be triggered by general anesthesia and pain medications (intravenous and oral routes), specifically opiates and sedatives, in patients who were previously stable yet having impaired baseline respiratory function. These findings highlight the need for careful perioperative management of patients with DM1.

Except for excessive daytime sleepiness, which can be the presenting symptom in some patients [19] in part of central origin $[10-12,14]$, symptoms of DM1 respiratory involvement are less likely to be presented as a complaint in some cases because DM1 is a slow progressing disorder $[3,20]$ and patients adapt to unusually high levels of daytime hypercapnia and bulbar muscle weakness $[21,22]$. It is not unusual to find patients on first evaluation in the outpatient clinic in whom blood $\mathrm{CO}_{2}$ levels are above the normal range on arterial blood gas analysis and who are not complaining of symptoms immediately related to respiratory involvement. The main complaint may be fatigue or tiredness or excessive sleepiness during the day. The majority of patients will usually rule out sleep problems because falling asleep at night is not typically present just as oversleeping in the morning is frequent for the majority of these patients. The passive-avoidant behaviors and apathy, which often characterize these patients may in part account for this, because it may limit the perception of respiratory-associated abnormalities that may be present. Finally, because of these considerations, when nocturnal non-invasive ventilation (NIV) or cough-assisted devices are prescribed, adherence to therapy is typically limited in many patients with DM1. A recent systematic review of respiratory dysfunction in DM1 [22] has summarized the current literature on this topic and has identified the gaps for future research direction including the limited data on natural history including respiratory progression and the mechanisms explaining the central versus peripheral components or the role of expansion in the respiratory disease mechanisms.

The aim of the present report is to provide specific indications for pulmonologists who may not have experience with patients with DM1 on which tests to perform at diagnosis and at follow-up, which are the symptoms to look for, considering the limited complaints these patients may have, and how and when to monitor them over time. This should improve care of patients with DM1 and should reduce the risk of respiratory complications that represent the main cause of death in these patients.

\section{Methods}

Myotonic recruited clinicians from the United States, the United Kingdom, Canada, and EU who had experience and knowledge in respiratory care and in myotonic dystrophy patient management to address clinical care guidance, update the 207th preliminary protocols [15] and develop consensus-based respiratory care recommendations for adults with DM1.

The project included a total Working Group of 12 clinical professionals. Myotonic provided project design, development and management support. A complete list of Working Group members and authors is listed in acknowledgments.

The principles of the Single Text Procedure were mainly adopted to steer the consensus-building process [23]. The Single Text Procedure employs the use of a single document as a starting point to incorporate the input and contributions of stakeholders. In this approach, stakeholders add, subtract, and refine a draft text through an iterative process that becomes the foundation for a final ratified document. 
This consensus-building model was selected because it could be effective within the context of the limited clinical care data available for respiratory care management in DM patients, the clinical content already available, and the complexities of working across an international group of experts [20].

Having already developed consensus-based care recommendations for DM1 [2], Myotonic created an in-depth document for respiratory care based on DM1-consensus care recommendations (for further methodological details refer to the Consensus-based Care Recommendations for Adults with DM1, 2018, www.myotonic.org/clinical-resources). The purpose of this document is to provide practical respiratory details and suggestions that were not addressed in the general care recommendations report for general physicians or non-neuromuscular neurologists and that are expected to be of use for pulmonologists or respiratory physiotherapists who may not be familiar with patients with DM1 but who need to perform tests on them at diagnosis and at follow-up.

Myotonic circulated the draft document to Working Group members. Working Group members read the draft content and provided edits and additional content. Myotonic aggregated all the revisions into a single updated document. Recommendations in conflict were circulated to the group for discussion and resolved through serial conference calls.

These efforts led to the final Consensus-based Care Recommendations for DM1, which were published in September 2018. The resulting recommendations are below. See the online supplementary Appendix for flow charts (for all online suppl. material, see www.karger.com/doi/10.1159/000505634) and other infographics for ease of use.

\section{Results}

Consensus-Based Care Recommendations for Pulmonologists Treating Adults with DM1 (Table 1):

1 Look for:

(a) Respiratory symptoms that may indicate:

(i) Nocturnal hypoventilation (poor sleep, morning headaches, orthopnea, excessive daytime sleepiness).

(ii) Obstructive sleep apnea (snoring, witnessed apneas, gasping/choking from sleep, poor sleep, excessive daytime sleepiness).

(iii) Decreased respiratory reserve or decreasing respiratory muscle function (dyspnea, orthopnea, tachypnea, fatigue, exercise intolerance).

(iv) Ineffective cough (decreased ability to cough, coughing when eating or drinking, choking, history of excessive frequency and duration of chest infections, including hospitalizations).

(b) Physical examination results indicative of respiratory muscle weakness and/or increased risk of obstructive sleep apnea. Important aspects to assess include at minimum resting respiratory rate, pulse oximetry, auscultation, assessment of chest wall motion, evaluation of accessory and abdominal muscle recruitment and breathing pattern. Signs of diaphragmatic paralysis should be evaluated, particularly whether there is orthopnea and/or tachypnea or paradoxical breathing when lying flat.

(c) Results from questionnaires covering symptoms of respiratory muscle weakness or sleep-disordered breathing (SDB; Epworth Sleepiness Scale, Fatigue and Daytime Sleepiness Scale, RESPICHECK).

(d) The single breath count may also be used to evaluate pulmonary function.

(e) Assessment of cough strength is recommended.

Consider that patients with DM1 may not complain of respiratory symptoms and may not be aware of some until specifically questioned on them. Allocate more time than usually scheduled for patients with more common respiratory problems, to go over the symptoms with these patients. 2 Test for:

(a) Forced vital capacity (FVC) in the sitting and supine position if possible, every 6 months. Spirometry tests should be performed using either mouthpiece along with a nasal clip or a mask (if weakness of orbicularis oris muscle is present). In either instance, the device that provides the better fit should enable a more precise measurement. FVC is considered abnormal if $<80 \%$ of the predicted normal value, or if it falls by $>20 \%$ or $500 \mathrm{~mL}$ from sitting to supine [24].

(b) Maximum inspiratory pressure (MIP) and maximum expiratory pressure in the upright position, every 6 months. MIP value is considered abnormal if less than $-60 \mathrm{~cm} \mathrm{H}_{2} \mathrm{O}$, maximum expiratory pressure if $<40 \mathrm{~cm}$ $\mathrm{H}_{2} \mathrm{O}$. A nasal clip should be used. Sniff nasal inspiratory pressure can substitute for MIP if significant buccal weakness is present or if the patient is unable to tolerate the MIP test due to myotonia or other mitigating symptoms $[25,26]$.

(c) Cough peak flows (CPF), every 6 months. If CPF is $<270 \mathrm{~L} / \mathrm{min}$ in adult patients, then cough is relatively ineffective, and manual and/or mechanical cough assistance techniques should be implemented. If CPF is $<160$ $\mathrm{L} / \mathrm{min}$, the risk of pneumonia and respiratory failure is considered high, especially during intercurrent respiratory tract infections.

Consider that patients with DM1 may need additional time to understand the test procedure because of some degree of visual spatial and executive problems that may be present as part of their brain disease. It is appropriate to give examples to ensure proper execution during the test procedure and to allocate more time than usual to allow extra time for these patients to perform as best. 
Table 1. Summarizes the symptoms and assessments to consider when a patient with DM1 comes to an initial assessment of respiratory function

\begin{tabular}{|c|c|c|c|}
\hline Clinical feature & What to look for & How to test it & What to do with it \\
\hline Nocturnal hypoventilation & $\begin{array}{l}\text { Poor sleep } \\
\text { Morning headache } \\
\text { Orthopnea } \\
\text { Excessive daytime sleepiness }\end{array}$ & $\begin{array}{l}\text { Nocturnal oximetry } \\
\text { Sleep study } \\
\text { Morning arterial blood gas } \\
\text { analysis } \\
\text { ESS }\end{array}$ & NIV \\
\hline Obstructive sleep apnea & $\begin{array}{l}\text { Snoring } \\
\text { Apneas } \\
\text { Poor sleep } \\
\text { Excessive daytime sleepiness }\end{array}$ & $\begin{array}{l}\text { Nocturnal oximetry } \\
\text { Sleep study } \\
\text { ESS }\end{array}$ & CPAP or NIV \\
\hline $\begin{array}{l}\text { Decreased respiratory } \\
\text { function }\end{array}$ & $\begin{array}{l}\text { Dyspnea } \\
\text { Orthopnea } \\
\text { Tachypnea } \\
\text { Fatigue } \\
\text { Exercise intolerance }\end{array}$ & $\begin{array}{l}\text { Respiratory rate } \\
\text { Lung auscultation } \\
\text { Assessment of chest wall } \\
\text { motion } \\
\text { Pulse oximetry } \\
\text { Fatigue scale } \\
\text { Pulmonary function tests with } \\
\text { FVC both sitting and supine } \\
\text { Lung X-rays }\end{array}$ & $\begin{array}{l}\text { Lung volume recruitment with } \\
\text { air-stacking techniques } \\
\text { NIV } \\
\text { Reconditioning physical } \\
\text { exercise under PT supervision }\end{array}$ \\
\hline Ineffective cough & $\begin{array}{l}\text { Decreased ability to cough } \\
\text { Coughing after swallowing } \\
\text { while eating } \\
\text { History of recurrent chest } \\
\text { infections }\end{array}$ & $\begin{array}{l}\text { Peak expiratory flow } \\
\text { Peak cough expiratory flow } \\
\text { Swallowing study }\end{array}$ & $\begin{array}{l}\text { Air-stacking techniques } \\
\text { MAC techniques } \\
\text { In-exsufflator or cough } \\
\text { machine adaptation }\end{array}$ \\
\hline $\begin{array}{l}\text { Decreased respiratory } \\
\text { muscle strength }\end{array}$ & $\begin{array}{l}\text { Dyspnea } \\
\text { Decreased ability to cough } \\
\text { Fatigue } \\
\text { Exercise intolerance }\end{array}$ & $\begin{array}{l}\text { Assessment of accessory and } \\
\text { abdominal muscle } \\
\text { recruitment } \\
\text { Peak cough expiratory flow } \\
\text { Pulmonary function tests } \\
\text { including MIP and MEP } \\
\text { Fatigue scale }\end{array}$ & $\begin{array}{l}\text { Air-stacking techniques } \\
\text { Assisted cough techniques } \\
\text { NIV } \\
\text { Weight control } \\
\text { Posture control }\end{array}$ \\
\hline Diaphragmatic paralysis & $\begin{array}{l}\text { Orthopnea } \\
\text { Tachypnea while lying flat } \\
\text { Paradoxical breathing while } \\
\text { lying flat }\end{array}$ & $\begin{array}{l}\text { Assessment of chest wall } \\
\text { motion } \\
\text { Assessment of accessory and } \\
\text { abdominal muscle } \\
\text { recruitment } \\
\text { Lung X-rays }\end{array}$ & $\begin{array}{l}\text { NIV } \\
\text { Posture control } \\
\text { Surgery for selected cases }\end{array}$ \\
\hline Excessive daytime sleepiness & $\begin{array}{l}\text { Inactivity and activity } \\
\text { daytime sleepiness } \\
\text { interfering with daily } \\
\text { activities }\end{array}$ & $\begin{array}{l}\text { Multiple sleep latency test } \\
\text { Maintenance of wakefulness } \\
\text { test } \\
\text { ESS }\end{array}$ & $\begin{array}{l}\text { Modafinil } \\
\text { NIV } \\
\text { Sleep-wake cycle control } \\
\text { Life habits control }\end{array}$ \\
\hline
\end{tabular}

DM1, myotonic dystrophy type 1; ESS, Epworth Sleepiness Scale; FVC, forced vital capacity; MAC, manually assisted cough; MIP, maximum inspiratory pressure; MEP, maximum expiratory pressure.

(d) Nocturnal oximetry/capnography or polysomnography, every 6 months. This test is considered abnormal if the apnea hypopnea index exceeds 5 per hour. The Oxygen Desaturation Index is $>15$ events/h in adults.
Sleep studies are recommended in patients with suspected SDB, especially in the absence of nocturnal or daytime hypercapnia. Polysomnography is superior to polygraphy, since it allows for assignment of respiratory events 
to sleep stages. Oximetry alone is not suitable to identify patients with nocturnal hypoventilation, and overnight carbon dioxide monitoring is advisable. Transcutaneous capnometry most accurately reflects nocturnal $\mathrm{CO}_{2}$ changes. Blood gas analysis during the night or immediately after waking may show either hypercapnia or an elevated base excess reflecting renal bicarbonate retention.

(e) Daytime blood gas analysis, or end-tidal and/or transcutaneous $\mathrm{CO}_{2}$ analysis to evaluate for hypercapnia in patients with more advanced respiratory muscle weakness. Daytime hypercapnia is defined as $\mathrm{PaCO}_{2}>45 \mathrm{~mm}$ $\mathrm{Hg}$ or $>6.0 \mathrm{kPa}$, respectively.

(f) Indicators of SDB including snoring, witnessed apneas, gasping/chocking from sleep, nightly interrupted or fragmented sleep, a MIP value of $<60$ or an FVC of $<50 \%$ of predicted. If patients with DM1 have sleep-related symptoms such as excessive daytime sleepiness, fatigue, morning headaches or poor sleep, a full night polysomnography is recommended [27-33].

(g) Airway clearance capacity and other respiratory assessments prior to surgery. If needed, adaptation to nocturnal NIV or to mechanical insufflation-exsufflation devices should occur prior to surgery. See "Treat with" recommendation below for treatment parameters.

(h) Patient should be referred to a specialist in dysphagia evaluation if swallowing problems are suspected (cough before, during or after meals, food stagnation in the oral cavity, drooling, regurgitation of undigested food, aspiration, gurgling in the throat, dysphonia, malnutrition).

3 Treat with:

(a) Vaccinations for influenza and pneumonia (pneumococci, hemophilus) if no contraindications.

(b) Standard medical therapy, as well as cough assistance and mechanical ventilation (as needed) for respiratory support.

(c) Manual and/or mechanical cough assistance techniques (e.g., breath stacking, abdominal thrust, and the mechanical insufflator/exsufflator) for adult patients with DM1 having ineffective cough (cough peak flow of $<270 \mathrm{~L} / \mathrm{min}$ ), and during chest infections and perioperative periods. An intrapulmonary percussive (IPV) or high frequency chest wall oscillation (HFCW) device can be used as a supplement to the above cough assistance techniques but is insufficient if used without effective expectoration of mucus (Fig. 1).

(i) A manually assisted cough (MAC) uses either, or a combination of, a manual Heimlich/abdominal thrust maneuver and a manual thoracic compression to increase expiratory airflow. Limits of effectiveness for the use of
MAC in neuromuscular disorders have been reported (Chatwin 2018) when unassisted peak cough flow is MAC $\leq 140 \mathrm{~L} / \mathrm{min}$.

(ii) Insufflation techniques when FVC is $\leq 2 \mathrm{~L}$ or $\leq 50 \%$ predicted or if there is evidence of weak cough.

(iii) Air-stacking techniques if CPF are between 160 and $270 \mathrm{~L} / \mathrm{min}$ in order to increase cough efficacy (if the patient has glottic competence) or if there is evidence of weak cough.

(iv) Resuscitator bag with a one-way valve (AMBU) if patient can operate with hands, knees, or foot. Otherwise a caregiver is needed in order to help the patient perform the technique.

(v) Intermittent positive pressure ventilation, since these devices can be used by the patient alone, even with hand weakness; they require good lip strength to correctly hold the mouthpiece.

(vi) In-patients already using volume cycled ventilators: mouthpiece ventilation can be implemented for lung volume management and secretion clearance. The correct execution of the technique should be evaluated by measuring PCF with air-stacking maneuver: if results are $>270 \mathrm{~L} / \mathrm{min}$, the technique can be considered efficient for secretion management. Otherwise, mechanical cough assistance is the best strategy to increase cough efficacy (see Cough Management Guide).

(vii) Devices for secretion mobilization such as IPV and HFCW devices should be considered in excessive secretion encumbrance situations. IPV is an adaptation of high frequency percussive ventilation, which promotes airway vibrations by injecting rapid bursts of air into the lung via the mouth. IPV may be delivered via a face mask, a mouthpiece, an endotracheal tube, or a tracheostomy and it facilitates airway clearance and improves the homogeneity of ventilation in patients with neuromuscular disorders with retention of mucus.

HFCW devices generate either positive or negative trans-respiratory pressure excursions to produce highfrequency, small-volume oscillations in the airways. HFCWC can lead to changes in volume of $15-57 \mathrm{~mL}$ and in flow up to $1.6 \mathrm{~L} / \mathrm{s}$, which generate minimal coughing to mobilize secretions. The typical treatment lasts 20-30 min, and consists of short periods of compression at different frequencies, separated by coughing. Coughing should always be assisted with cough assistance techniques if ineffective.

Patients, and caregivers if needed, should be taught how and when to perform the above techniques at home.

(d) Nocturnal non-invasive ventilation (NIV) for respiratory insufficiency in patients who have respiratory 

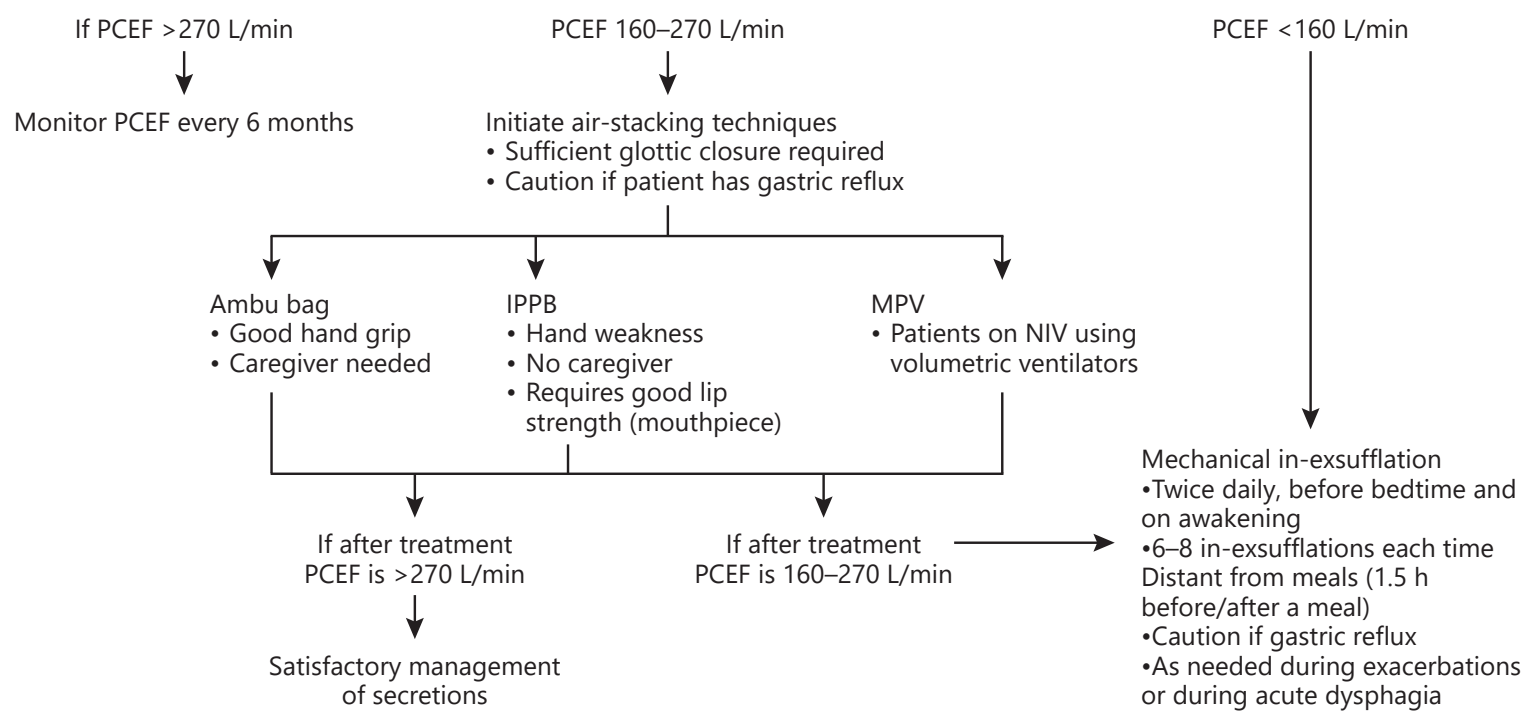

Fig. 1. Cough management guide. MPV, mouthpiece ventilation; PCEF, peak cough expiratory flow; IPPB, intermittent positive pressure breathing.

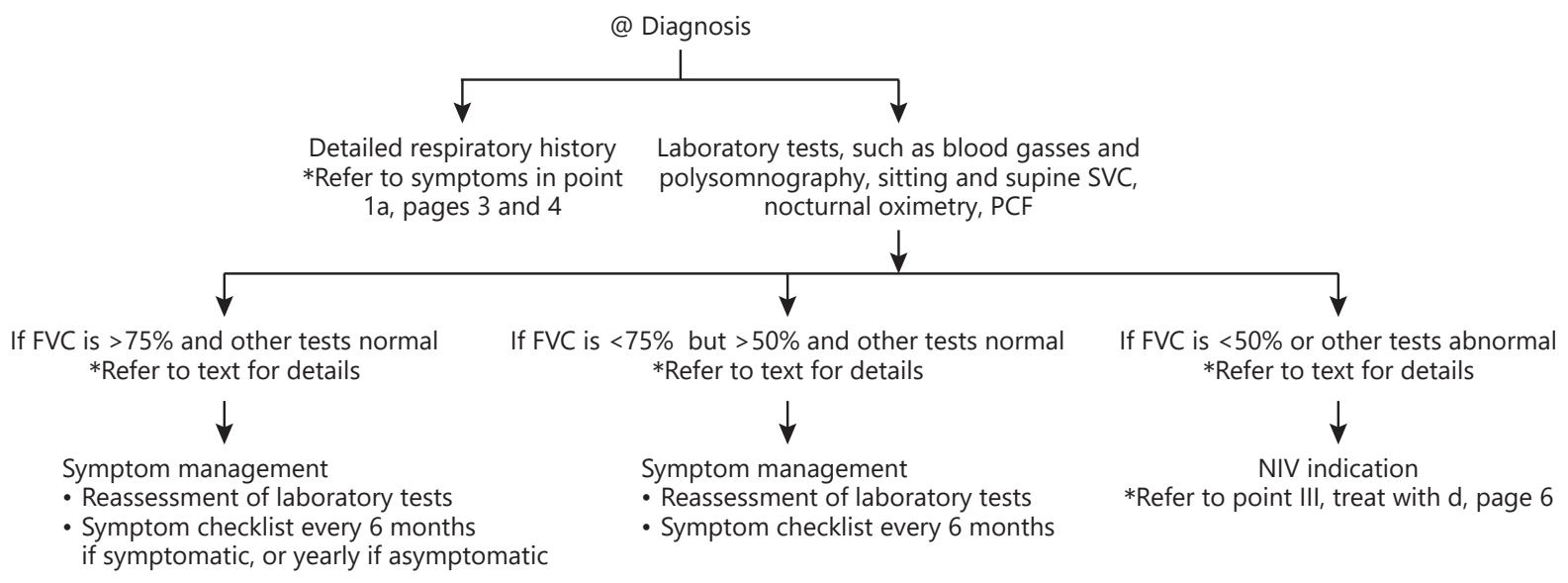

Fig. 2. Respiratory care flow sheet - from diagnosis. FVC, forced vital capacity; SVC, slow vital capacity; PCF, peak cough flow.

muscle weakness and sleep-related breathing disorders. According to the 207th European Neuromuscular Centre Workshop (2014-07-21), NIV should commence when there is at least one or more daytime or nighttime symptoms suggestive of chronic respiratory insufficiency in combination with (Fig. 2):

- Daytime hypercapnia, $\mathrm{PaCO}_{2} \geq 45 \mathrm{~mm} \mathrm{Hg}(6.0 \mathrm{kPa})$ or
- $\mathrm{FVC}<50 \%$ of predicted based on the best of 3 measures and MIP $<60 \mathrm{~cm} \mathrm{H}_{2} \mathrm{O}$ or

- Evidence of nocturnal hypoventilation, such as:

(i) A rise in $\mathrm{PaCO}_{2}$ of $\geq 10 \mathrm{~mm} \mathrm{Hg}$ ( $1 \mathrm{kPa}$ ) between evening and morning arterial blood gas measurements or other accurate $\mathrm{CO}_{2}$ surrogates.

(ii) A rise in transcutaneous $\mathrm{CO}_{2}$ to $>50 \mathrm{~mm} \mathrm{Hg}(6.7$ $\mathrm{kPa}$ ) for $>50 \%$ of total sleep time. 
(iii) While not ideal - when a measurement of $\mathrm{CO}_{2}$ is not available - continuous nocturnal oximetry demonstrating sustained oxygen desaturation $\left(\mathrm{SpO}_{2}\right) \leq 88 \%$ for 5 consecutive minutes or $\mathrm{SpO}_{2}<90 \%$ for $>10 \%$ of total sleep time.

(iv) An attended polysomnogram showing evidence of SDB with an apnea hypopnea index $>5$ events per hour and transcutaneous $\mathrm{CO}_{2}$ /end tidal $\mathrm{CO}_{2}$ changes as above.

(v) Some patients will progress from requiring nocturnal ventilatory support to daytime ventilatory support. With daytime ventilation, different mask interfaces or mouth piece ventilation are options.

(vi) Facial morphology should be considered in the choice of mask interface. In case of facial muscle weakness with difficulties in mouth closure, oronasal masks or nasal interfaces in association with chinstraps can be the best option in order to avoid excessive leaks (providing aspiration is not a significant concern). If NIV is also used during the daytime, mask rotation strategies and/or mouthpiece ventilation should be adopted to offload skin pressure points.

(vii) Adherence should be monitored and is usually based on a minimum threshold of $4 \mathrm{~h} /$ day. It is preferable to use NIV at night for sleep. Initially, some individuals may require desensitization to NIV during the day. Adherence to NIV has been reported to be lower specifically in patients with no subjective symptoms of respiratory insufficiency, with high body mass index or most frequently in the presence of excessive leaks and so special attention should be paid in these cases.

(viii) In the United States and other countries, recommendations for insurance reimbursement are contingent upon adherence review by the treating physician. Individuals must demonstrate NIV adherence by daily use of a minimum of $4 \mathrm{~h},>70 \%$ of the time during adherence review, within a 90-day period from the day the device is set up. Majority of insurance companies follow the U.S. Centers for Medicare and Medicaid guidelines for adherence and reimbursement.

At each follow-up visit after NIV adaptation, or if the patient complains of subjective symptoms of respiratory compromise, patients should be tested with overnight cardiorespiratory polygraphy and carbon dioxide monitoring either with NIV and/or arterial blood gas analysis, end tidal $\mathrm{CO}_{2}$ or transcutaneous $\mathrm{CO}_{2}$, if indicated. Symptoms of nocturnal hypoventilation should also be asked for from the patients. Downloaded data from NIV devices may also provide additional information about adequacy of ventilator support.

(ix) Supplemental oxygen should not be used alone or in conjunction with NIV unless there is specific lung pa- thology baseline $\mathrm{O}_{2}$ saturation cannot be normalized by airway clearance techniques or ventilatory setting adjustments. In this case, individuals must be evaluated for specific lung pathology that would explain the hypoxemia. Supplemental oxygen may need to be used with extreme caution without NIV in specific rare cases.

(e) Emergency medical alert card or bracelet.

(f) Whereas "NIV" has come to mean CPAP and/or low spans of bi-level PAP used to titrate away obstructive apnea and hypopneas, many myotonic dystrophy patients' vital capacities diminish to under $100 \mathrm{~mL}$ and require either high pressure support bi-level PAP (IPAP EPAP difference $>15 \mathrm{~cm} \mathrm{H}_{2} \mathrm{O}$ ) with back up respiratory rate modality, or volume cycled ventilation at full ventilator delivered volumes called noninvasive ventilatory support or "NVS." Therefore, tracheostomy should be considered only for patients who are dependent on noninvasive ventilatory support $24 \mathrm{~h} /$ day and are not suitable candidates for daytime ventilation either with mask interface or mouth piece ventilation (i.e., sip ventilation). Tracheostomies must be managed in order to maintain swallowing and speech.

(i) If possible, a tube with deflatable cuff can be used to permit speech.

(ii) Speaking valves can also be used to improve speech during spontaneous breathing, but this may be dangerous in the home setting without appropriate education and monitoring.

(g) Progressive weaning after acute respiratory distress or after surgery.

(i) After acute respiratory distress:

1 Weaning must be progressive.

2 Spontaneous breathing trials may be considered (depending on patient's respiratory status prior to surgery or acute event) for evaluation of the patient's weaning capacity; however, patients do not need to be weaned from the ventilator to be successfully extubated, as extubation directly to NIV with aggressive use of mechanically assisted cough is recommended. Patients can wean to "baseline" by taking fewer and fewer "sip ventilation" or stay on shorter periods of nasal NIV.

3 Do not use NIV with pressure support in a spontaneous mode (i.e., without back up rate) due to the importance of backup respiratory rate in case of central apnea or respiratory drive impairment.

4 Consider airway clearance techniques such as mechanical insufflation-exsufflation as a lung volume recruitment strategy in addition to airway clearance in preparation for extubation, and to prevent re-intubation. 
5 Patients should be extubated to their own ventilatory devices at their usual settings.

(ii) After surgery:

1 Extubation should not be done on the operation table immediately after anesthesia.

2 Extubation should be done in a recovery room or intensive care unit due to side effects of anesthetics and morphinics in DM1; (See Myotonic's Anesthesia Guidelines).

3 Consider airway clearance maneuvers before and after extubation.

4 Patient can be extubated to their own ventilatory device if the patient was previously using ventilatory support.

\section{Conclusions}

These Consensus-based Respiratory Care Recommendations for Pulmonologists Treating Adults with DM1 are the product of an international group of experienced clinicians. They are intended to lead to more informed and prepared clinical professionals, and more readily available and high-quality care for affected families. In particular, they should provide guidelines for patients who do not complain of respiratory symptoms at baseline but who may present with acute respiratory failure during infections and prior to surgery, avoiding unexpected tracheostomy.

Natural history studies on respiratory progression and cost-benefit analysis of respiratory management including implementation of NIV for patients having chronic respiratory insufficiency yet not complaining of respiratory symptoms, will confirm or refute the application of the existing respiratory protocols for patients with DM1 considering benefits, risks, harm, and cost of what is so far recommended.

\section{Acknowledgments}

This project would not have been possible without the significant commitment made by the international professionals involved in its development. The full list of members is given below. M.B., M.C., E.D.M., E.F., M.G., V.H., S.L.K., D.M., D.O., G.S., V.S., P.W., and L.H.

\section{Statistical Analysis}

N/A.

\section{References}

1 Harper P. Myotonic dystrophy. 3rd ed. London: WB Saunders; 2001.

2 Ashizawa T, Gagnon C, Groh WJ, Gutmann L, Johnson NE, Meola G, et al. Consensusbased care recommendations for adults with myotonic dystrophy type 1 . Neurol Clin Pract. 2018 Dec;8(6):507-20.

3 Hilton-Jones D. Myotonic dystrophy-forgotten aspects of an often neglected condition. Curr Opin Neurol. 1997 Oct;10(5):399-401.

4 de Die-Smulders CE, Höweler CJ, Thijs C, Mirandolle JF, Anten HB, Smeets HJ, et al. Age and causes of death in adult-onset myotonic dystrophy. Brain. 1998 Aug;121(Pt 8): 1557-63.

5 Mathieu J, Allard P, Potvin L, Prévost C, Bégin P. A 10-year study of mortality in a cohort of patients with myotonic dystrophy. Neurology. 1999 May;52(8):1658-62.

6 Groh WJ, Groh MR, Shen C, Monckton DG, Bodkin CL, Pascuzzi RM. Survival and CTG repeat expansion in adults with myotonic dystrophy type 1. Muscle Nerve. 2011 May; 43(5):648-51.

7 Giubilei F, Antonini G, Bastianello S, Morino S, Paolillo A, Fiorelli M, et al. Excessive daytime sleepiness in myotonic dystrophy. J Neurol Sci. 1999 Mar;164(1):60-3.
8 Phillips MF, Steer HM, Soldan JR, Wiles CM, Harper PS. Daytime somnolence in myotonic dystrophy. J Neurol. 1999 Apr;246(4):275-82.

9 Shneerson JM, Simonds AK. Noninvasive ventilation for chest wall and neuromuscular disorders. Eur Respir J. 2002 Aug;20(2):480-7.

10 Romigi A, Izzi F, Pisani V, Placidi F, Pisani LR, Marciani MG, et al. Sleep disorders in adult-onset myotonic dystrophy type 1: a controlled polysomnographic study. Eur J Neurol. 2011 Sep;18(9):1139-45.

11 Yu H, Laberge L, Jaussent I, Bayard S, Scholtz $S$, Raoul M, et al. Daytime sleepiness and REM sleep characteristics in myotonic dystrophy: a case-control study. Sleep (Basel). 2011 Feb; 34(2):165-70.

12 Laberge L, Dauvilliers Y, Bégin P, Richer L, Jean S, Mathieu J. Fatigue and daytime sleepiness in patients with myotonic dystrophy type 1: to lump or split? Neuromuscul Disord. 2009 Jun;19(6):397-402.

13 Laberge L, Bégin P, Dauvilliers Y, Beaudry M, Laforte $\mathrm{M}$, Jean S, et al. A polysomnographic study of daytime sleepiness in myotonic dystrophy type 1. J Neurol Neurosurg Psychiatry. 2009 Jun;80(6):642-6.
14 Bianchi ML, Losurdo A, Di Blasi C, Santoro M, Masciullo M, Conte G, et al. Prevalence and clinical correlates of sleep disordered breathing in myotonic dystrophy types 1 and 2. Sleep Breath. 2014 Sep;18(3):579-89.

15 Sansone VA, Gagnon C2; participants of the 207th ENMC Workshop. 207th ENMC Workshop on chronic respiratory insufficiency in myotonic dystrophies: management and implications for research, 27-29 June 2014, Naarden, The Netherlands. Neuromuscul Disord. 2015 May;25(5):432-42.

16 Ercolin B, Sassi FC, Mangilli LD, Mendonça LI, Limongi SC, de Andrade CR. Oral motor movements and swallowing in patients with myotonic dystrophy type 1. Dysphagia. 2013 Sep;28(3):446-54.

17 Cho HE, Lee JW, Kang SW, Choi WA, Oh H, Lee KC. Comparison of Pulmonary Functions at Onset of Ventilatory Insufficiency in $\mathrm{Pa}$ tients With Amyotrophic Lateral Sclerosis, Duchenne Muscular Dystrophy, and Myotonic Muscular Dystrophy. Ann Rehabil Med. 2016 Feb;40(1):74-80.

18 Boentert M. Dissecting the benefits of longterm non-invasive ventilation in patients with distinct neuromuscular disorders. Respirology. 2017 Oct;22(7):1251-2. 
19 Heatwole C, Bode R, Johnson N, Quinn C, Martens W, McDermott MP, et al. Patientreported impact of symptoms in myotonic dystrophy type 1 . Neurology. 2012 Jul;79(4): 348-57.

20 Harper PS, van Engelen BG, Eymard B, Rogers M, Wilcox D. 99th ENMC international workshop: myotonic dystrophy: present management, future therapy. 9-11 November 2001, Naarden, The Netherlands. Neuromuscul Disord. 2002 Aug;12(6):596-9.

21 Poussel M, Thil C, Kaminsky P, Mercy M, Gomez E, Chaouat A, et al. Lack of correlation between the ventilatory response to $\mathrm{CO} 2$ and lung function impairment in myotonic dystrophy patients: evidence for a dysregulation at central level. Neuromuscul Disord. 2015 May;25(5):403-8.

22 Hawkins AM, Hawkins CL, Abdul Razak K, Khoo TK, Tran K, Jackson RV. Respiratory dysfunction in myotonic dystrophy type 1: A systematic review. Neuromuscul Disord. 2019 Mar;29(3):198-212.

23 Smith MS. Single Text Negotiation. In: Beyond Intractability. Conflict Information Consortium, University of Colorado, Boulder. [Posted July 2005]. Available from: https://www.beyondintractability.org/essay/ single-text-negotiation.
24 Hull J, Aniapravan R, Chan E, Chatwin M, Forton J, Gallagher J, et al. British Thoracic Society guideline for respiratory management of children with neuromuscular weakness. Thorax. 2012 Jul;67(1 Suppl 1):1-40.

25 American Thoracic Society/European Respiratory Society. ATS/ERS Statement on respiratory muscle testing. Am J Respir Crit Care Med. 2002 Aug;166(4):518-624.

26 Evans JA, Whitelaw WA. The assessment of maximal respiratory mouth pressures in adults. Respir Care. 2009 Oct;54(10):134859.

27 Monteiro R, Bento J, Gonçalves MR, Pinto T, Winck JC. Genetics correlates with lung function and nocturnal ventilation in myotonic dystrophy. Sleep Breath. 2013 Sep;17(3): 1087-92.

28 Boussaïd G, Lofaso F, Santos DB, Vaugier I, Pottier S, Prigent H, et al. Factors influencing compliance with non-invasive ventilation at long-term in patients with myotonic dystrophy type 1: A prospective cohort. Neuromuscul Disord. 2016 Oct;26(10):666-74.
29 Thil C, Agrinier N, Chenuel B, Poussel M. Longitudinal course of lung function in myotonic dystrophy type 1. Muscle Nerve. 2017 Oct;56(4):816-8.

30 Bonanni E, Carnicelli L, Crapanzano D, Maestri M, Simoncini C, Baldanzi S, et al. Disruption of sleep-wake continuum in myotonic dystrophy type 1: Beyond conventional sleep staging. Neuromuscul Disord. 2018 May; 28(5):414-21.

31 O’Donoghue FJ, Borel JC, Dauvilliers Y, Levy P, Tamisier R, Pépin JL. Effects of 1-month withdrawal of ventilatory support in hypercapnic myotonic dystrophy type 1 . Respirology. 2017 Oct;22(7):1416-22.

32 Lazarus A, Varin J, Jauvert G, Alonso C, Duboc D. Relationship between cardiac arrhythmias and sleep apnoea in permanently paced patients with type I myotonic dystrophy. Neuromuscul Disord. 2007 May; 17(5): 392-9.

33 Kaminska M, Browman F, Trojan DA, Genge A, Benedetti A, Petrof BJ. Feasibility of Lung Volume Recruitment in Early Neuromuscular Weakness: A Comparison Between Amyotrophic Lateral Sclerosis, Myotonic Dystrophy, and Postpolio Syndrome. PM R. 2015 Jul; 7(7):677-84. 